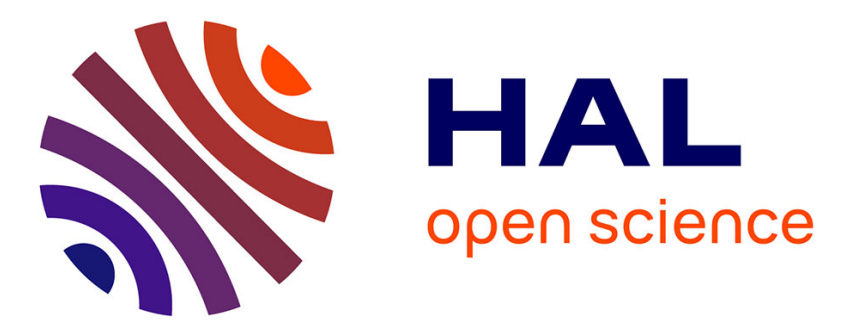

\title{
Services, Service Innovation and the Ecological Challenge
}

Faridah Djellal, Faïz Gallouj

\section{To cite this version:}

Faridah Djellal, Faïz Gallouj. Services, Service Innovation and the Ecological Challenge. in Faïz Gallouj and Faridah Djellal (eds) (2018), A Research Agenda for Service Innovation, Edward Elgar Publishers, 2018. hal-01672570

\section{HAL Id: hal-01672570 https://hal.science/hal-01672570}

Submitted on 26 Dec 2017

HAL is a multi-disciplinary open access archive for the deposit and dissemination of scientific research documents, whether they are published or not. The documents may come from teaching and research institutions in France or abroad, or from public or private research centers.
L'archive ouverte pluridisciplinaire HAL, est destinée au dépôt et à la diffusion de documents scientifiques de niveau recherche, publiés ou non, émanant des établissements d'enseignement et de recherche français ou étrangers, des laboratoires publics ou privés. 


\title{
Services, Service Innovation and the Ecological Challenge
}

\author{
Faridah Djellal and Faïz Gallouj
}

\section{INTRODUCTION}

Ever since their advent, Service Studies, followed by Service Innovation Studies, have highlighted a number of myths (often as a preamble to calling them into question). Though (partially) false, these myths are widely-accepted, idealized representations of the nature and socio-economic effects of services. Essentially, they are negative assessments reflecting a perception of services as inferior to goods, from various angles. The main (negative) myths in question, extensively debated in the literature (see Gallouj, 2002), are as follows: services are perceived as unproductive, non-capital-intensive and characterized by a low productivity level, as well as being unfit for international trade, weak on innovation and sources of low skill-level jobs, thus contributing to a "society of servants" (Gorz, 1988)...

A positive myth has since emerged in opposition to these negative myths, expressing the idea that services are naturally less harmful to the environment (greener) than material goods. This positive assessment of services is grounded in theoretical arguments relating to the fundamental nature of service activities, and in particular to their immateriality (Claval, 2006; Illeris, 2007; Rifkin, 2000; OECD, 2000; Ellger and Scheiner, 1997), as well as in statistical findings that, though scarce, are quite evocative. Thus, the tertiary sector's "ecological footprint" ${ }^{\text {"1 }}$ is considerably lower than that of industrial and agricultural production (Claval, 2006; Gadrey, 2004). Furthermore, estimates by the International Energy Agency (2008) show that globally, for 2005, services (excluding transport) accounted for only $9 \%$ of total final energy consumption and $12 \%$ of $\mathrm{CO}_{2}$ emissions.

While most negative myths about services have been the subject of extensive literature over two decades, the same cannot be said of the positive "green services" myth. The objective of this chapter is thus to identify a number of research avenues likely to deconstruct it. The chapter is broken down into three parts; in the first, we account for the foundations of this myth by examining its different facets. In the second and third parts, we propose some preliminary elements of a research agenda on services and service innovation in their relationship to ecological issues. The second part raises the question of the hidden sources of materiality of services, and the third, the question (closely linked to innovation dynamics) of the various possible ways of constructing immateriality - and thus of 'greening' services.

\subsection{MYTHS ABOUT SERVICES AS THEY RELATE TO ECOLOGICAL ISSUES}

The ecological problem has been established on the basis of increasing social disapproval of an industrial activity that engulfs non-renewable natural resources and discharges ever-

\footnotetext{
${ }^{1}$ The "ecological footprint" is a rough indicator that assesses the surface area of the planet necessary to carrying out the corresponding activities, given their consumption and emissions.
} 
increasing volumes of polluting emissions and environmentally-harmful waste. Services have long been absent from these debates; the economics of services and ecology are thus two fields of research that have long since ignored one another. This 'a-ecological' nature of Services Studies can be explained by the allegedly green nature of services. It is expressed at various analytical levels: macroeconomic, microeconomic, as well as at a finer level we might term 'genetic', insofar as it refers to an internal technical characteristic attributed to services - namely their immateriality.

\subsubsection{The green character of services at macroeconomic level: tertiarization as a mechanical factor in sustainability?}

In our economies, industrial activities (the main source of both natural resource consumption, and emissions) are losing out to service activities (said to be less harmful to the environment). Macroeconomic observation of the ineluctable tertiarization of contemporary economies thus leads a certain number of authors (Ettighoffer, 1992; Romm et al., 1999) to assume a mechanical evolution towards more sustainable economies. This seductive hypothesis of a mechanical relationship between tertiarization and ecological sustainability is also conveyed by certain international institutions, such as the OECD (OECD, 2000).

Though ecological concerns are not explicitly formulated in the post-industrial theory put forward by Daniel Bell (Bell, 1973), the premises of these concerns may be implicitly derived from it. Indeed, the post-industrial society is one in which inferior material services (transportation, retailing, etc.) give way to superior intellectual and intangible services (administrative services, health services, research services, cultural, leisure, etc.). In this society, Bell predicts the disappearance of the working class (blue collar workers), specialized in material processing, and the supremacy of intellectual and administrative workers (white collar workers), more oriented towards the processing of information and knowledge.

This ecologically optimistic (green) view of a structural dynamic in which tertiarization is synonymous with dematerialization and ecological sustainability is also implicit in the idea of an evolution towards a 'new' economy, the self-same reality designated in the literature by a range of terms: intangible economy, information economy, knowledge economy, etc. It should be noted that the informational paradigm constituting the basis of many innovation trajectories in contemporary economies is often described as intrinsically embedding a logic of 'dematerialization'. Informational innovation trajectories thus seem to evolve according to processes of increasing dematerialization, insofar as hardware declines in importance in comparison to software. It was this bivalence of the informational paradigm that inspired Baumol et al. (1985) to scale up the so-called "unbalanced growth model" by introducing an asymptotically stagnant sector (ICT).

A number of arguments contradict the "green services" assumption at the macroeconomic level. Indeed, the tertiary sector's "ecological footprint" seems to be massively underestimated, and is strongly affected by such services activities as transport, trade and tourism. More generally, it is undeniable that the most tertiarized contemporary economies are also those responsible for the most pollution. Baumol (2010) also introduced a further macroeconomic argument: according to this author, the chronic inflation (the cost disease) that affects services precisely because of their lower technological intensity can explain the pollution that affects contemporary economies. Indeed the high costs of goods repair services 
lead consumers to prefer the purchase of new goods over their repair. Contemporary services economies are thus "throwaway societies".

\subsubsection{The green character of services at microeconomic level: the end of the factory and the end of the machine?}

At microeconomic level, popular metaphors reflect the idea that tertiarization is synonymous with sustainability: "the end of the factory" or "the end of the machine" (at least in its heavy mechanical form). The images conveyed by these metaphors are clear. The economy of services is supposed to favour production spaces that are 'softer' than the factory that destroys natural space and is encumbered with cumbersome technical systems. The archetype of these new spaces would be the office - which from an ecological point of view, is considered more friendly than the factory.

Of course, there is no shortage of examples calling into question such a conclusion by highlighting service infrastructures, which in terms of environmental nuisances are comparable to certain industrial infrastructures: an airport hub or hypermarket, for example.

The macroeconomic phenomenon of tertiarization also manifests itself at microeconomic level through the creation of service companies. Indeed, in contemporary economies, most enterprise creation happens in the tertiary sector. However, this tertiarization phenomenon also manifests itself at micro level via a tendency to transform traditional industrial companies into service companies, since most of their added value is derived from the supply of services rather than the manufacture and sale of goods. For a long time, IBM and Benetton constituted the emblematic figures of this type of metamorphosis, in which the assembly plant is supplanted by the (design) office.

\subsubsection{The green character of services at 'genetic' level: is immateriality synonymous with sustainability?}

The green nature of both services and the tertiary sector, expressed at both macro and micro levels, is supposed to be explained by the intrinsic characteristics of the service activity. Using a genetic metaphor, we can say that this green nature expresses - at macro and micro economic levels - the phenotype of a genotype whose essential component is the supposed immateriality of the service. The reasoning entailing translating this genotype (immateriality) into an environment-friendly phenotype is obvious. The service - naturally immaterial, evanescent, transitory, disembodied - would not degrade the environment as industrial and agricultural activities do when they transform rare and non-renewable raw materials into material goods, damaging the natural environment in the course of both production and consumption.

The immateriality of the service - supposedly justifying its 'sustainability' (as opposed to the 'materiality' of goods) is at the heart of the definition of the service in both economics and management and is rooted in the work of classical economists. Jean-Baptiste Say (1972 [1803]) first used the "immaterial" qualifier to describe services. But the idea is implicitly present in the work of Adam Smith (1960) [1776], who is considered its precursor.

Even if, as we have shown in the previous section, the hypothesis of a causal link between immateriality of services and environmental sustainability appears to be a myth, our conclusion is not that services are harmful to the environment. Rather, our hypothesis is 
simply that, in the current state of research, the relationship is fairly indeterminate. It is therefore necessary to continue research efforts on this issue, and we now suggest a number of avenues in need of exploration (or further exploration). If the idea of a correlation between materiality and negative ecological sustainability is acceptable, then the problem to be solved in order to draw a conclusion can be broken down into two questions, the first focusing on a mapping perspective (in statics and in dynamics), and the second on a strategic perspective: 1) Are there neglected sources of materiality within services? 2) Can service immateriality be the target of proactive innovation strategies? These two questions constitute interesting general avenues for research.

\subsection{IN SEARCH OF HIDDEN SOURCES OF MATERIALITY IN SERVICES}

The first research perspective envisaged consists of seeking to map the materiality 'deposits' that characterize the service, in statics and dynamics. This analytical exercise is in itself a promising research avenue, not yet explored in sufficient depth (exceptions include Gadrey, 2010; Fourcroy et al., 2012, 2015; Djellal and Gallouj, 2016). It paves the way for particularly interesting fields of empirical, methodological and political research.

\subsubsection{Analytical identification of the forgotten sources of materiality}

Generally speaking, the service is not incorporated into physical devices capable of circulating economically (for example, being resold or retroceded) independently of the service medium/target. A car owner, for example, can not resell or retrocede the repair service performed on his/her vehicle without transferring the vehicle itself. Nor can a patient having undergone surgery transfer that surgery to a third party. The fact that a service (unlike a product) may not be consubstantial with its material components does not preclude close relationships with a number of material artefacts.

Gadrey 2010 (see also Fourcroy et al., 2012, 2015 and Djellal and Gallouj, 2016) identifies four often forgotten deposits of service materiality that are in need of both empirical and theoretical exploration (See Figure 2.1): 1) service delivery medium/target, 2) production factors (technical systems) mobilized during service provision, 3) service physical production and consumption spaces, and 4) travel required for performance of the service. It should be stressed that this fourth source of materiality lies at an analytical level that differs from the other three. It is transverse to them, insofar as travel can be based on transport and logistics technical systems, production and consumption spaces (stations, roads, motorways), etc. This is why, rather than being represented as a layer in Figure 2.1, it is integrated into the other layers. 


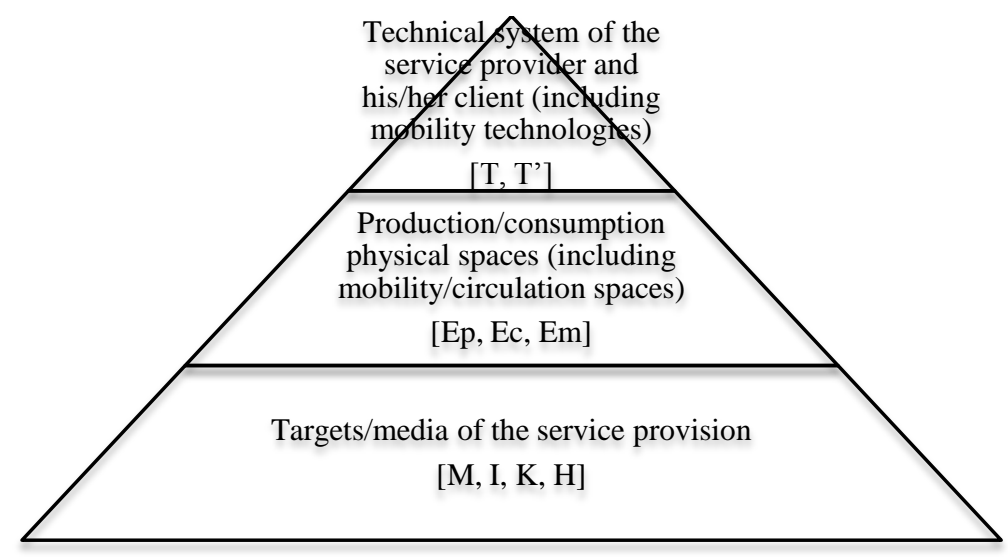

Figure 2.1: The various materiality 'deposits' in service provision

\section{Materiality of the service medium/target}

According to the definition established by Gadrey (1991), service delivery operates on a medium (or target) that it aims to transform in different ways. This medium can take the form of immaterial media/targets, such as codified information (I) or knowledge (K), but can also take the form of human $(\mathrm{H})$ or physical $(\mathrm{M})$ targets - for example a product or technical system. This service target typology underlies a number of service typologies. Depending on the main medium involved $(\mathrm{M}, \mathrm{I}, \mathrm{K}$ or $\mathrm{H})$, the following four types of services can, for example, be distinguished (Gadrey, 1996): (1) material processing services, (2) individual processing services, (3) information processing services, (4) organizational knowledge processing services. These different types of services are defined and illustrated in Table 2.1. It is important to emphasize that each type of service is defined by the main medium processed. In reality, however, all service activities are carried out in varying and evolutive proportions on all possible media: material, informational, cognitive and human (we will return to this point in Section 3.2).

Table 2.1: A typology of services according to the level of materiality of their main medium

\begin{tabular}{|l|l|l|l|}
\hline \multicolumn{1}{|c|}{ Type of service } & \multicolumn{1}{|c|}{$\begin{array}{c}\text { Main } \\
\text { medium/target: M, } \\
\mathbf{I}, \mathbf{K}, \mathbf{H}\end{array}$} & \multicolumn{1}{|c|}{ Medium processing } & \multicolumn{1}{c|}{ Examples } \\
\hline $\begin{array}{l}\text { Materials } \\
\text { processing } \\
\text { services }\end{array}$ & $\begin{array}{l}\text { M: a tangible object } \\
\text { a good, a technical } \\
\text { system...) }\end{array}$ & $\begin{array}{l}\text { Transport, transfer, } \\
\text { repair }\end{array}$ & $\begin{array}{l}\text { Freight transportation, automotive } \\
\text { repair, retailing, catering, supply of } \\
\text { water, gas and electricity }{ }^{2} \text { garbage } \\
\text { collection, cleaning, sanitation, } \\
\text { various types of rentals, etc. }\end{array}$ \\
\hline $\begin{array}{l}\text { Individuals } \\
\text { processing } \\
\text { services }\end{array}$ & $\begin{array}{l}\text { H: the individual } \\
\text { himself }\end{array}$ & $\begin{array}{l}\text { Transform locational, } \\
\text { aesthetic, emotional, } \\
\text { intellectual, } \\
\text { dimensions, etc. } \\
\text { health }\end{array}$ & $\begin{array}{l}\text { Health services, elderly care, } \\
\text { passenger transportation, education, } \\
\text { recreation, beauty services, etc }\end{array}$ \\
\hline $\begin{array}{l}\text { Information } \\
\text { processing } \\
\text { services }\end{array}$ & $\begin{array}{l}\text { I: codified } \\
\text { information }\end{array}$ & $\begin{array}{l}\text { Produce, enter, transport, } \\
\text { etc. }\end{array}$ & $\begin{array}{l}\text { Banking services, insurance, public } \\
\text { administration, etc. }\end{array}$ \\
\hline
\end{tabular}

\footnotetext{
${ }^{2}$ These services have a certain material dimension, though, especially in the case of electricity, they are not tangible objects.
} 


\begin{tabular}{|l|l|l|l|}
\hline $\begin{array}{l}\text { Organizational } \\
\text { knowledge } \\
\text { processing } \\
\text { services }\end{array}$ & $\begin{array}{l}\text { K: the knowledge of } \\
\text { organizations }\end{array}$ & $\begin{array}{l}\text { Produce, maintain, } \\
\text { capitalize, etc. }\end{array}$ & $\begin{array}{l}\text { Various forms of consultancy, R\&D, } \\
\text { engineering, advertising services }\end{array}$ \\
\hline
\end{tabular}

In this typology, services primarily concerned with material processing (freight transport, catering, car repair, etc.) appear a priori to be more 'material' and less 'green' than intellectual services (especially organizational knowledge processing services). It should be noted that individual processing services are not homogeneous in their relationship to materiality/sustainability. Indeed, three sub-groups (each having different materiality levels) can be distinguished within this category: individuals considered in their spatial location (transport of persons, tourism); individuals considered in their aesthetic, emotional and health status (health services, hairdresser, leisure services); individuals considered in their state of knowledge (education). The degree of materiality of these three sub-groups is decreasing and, in its relationship to sustainability, the first subgroup is no different in any way from certain material processing services (such as freight transport).

\section{Materiality of the technical systems mobilized}

Whether they primarily relate to a material or non-material medium, services are subject to another essential source of materiality. In being carried out, they mobilize more or less numerous production factors. Though human resources have an obvious physiological materiality, our focus here is on the materiality of technical systems. These may belong to the provider [T] or customer [ $\left.\mathrm{T}^{\prime}\right]$. The operation of these technical systems, used by service companies and organizations as well as their customers, requires energy and other raw material consumption (such as paper and ink cartridges for printers). It causes emissions and waste. Moreover, as we will see in Section 2.2, these technical systems are the result of traditional industrial production processes, which are particularly harmful to the environment and which consume energy and exhaustible natural resources (rare metals in IT, for example). While information technologies play an essential role in services, where they are considered invasive, they should not lead to a minimization of the role of other technologies (for transport, cooking, refrigeration, heating, biotechnology, etc.). We should be aware that focusing on a single facet of materiality can be misleading. For example, informational services (banking, insurance, administration), whose main medium (codified information) is intangible are among the main users of information technologies - renowned for their hefty ecological footprint.

\section{The materiality of the production/consumption physical spaces}

Another important source of materiality and ecological harm (destruction of natural spaces, aesthetic damage, energy consumption, etc.) in services are the physical production and consumption spaces for service provision (Ep, Ec). A good illustration of this source of materiality is provided by the hypermarkets that have flourished outside major cities in recent decades. Other examples are air transportation hubs, university campuses and large hospital complexes. It is also possible to include within the materiality of these production/consumption spaces the materiality of interior architecture, as well as the many supplies necessary to carrying out the service in back or front office. These production/consumption spaces consume energy for heating, cooling, lighting, etc. Furthermore, both the upstream production process and the downstream maintenance process for these spaces and their supplies are particularly damaging to the environment (see Paragraph 2.2). 


\section{Mobility-related materiality}

The final source of materiality discussed here is travel - which often proves necessary to the establishment of the service relationship and service provision. The anti-ecological dimension of mobility naturally increases in line with geographical distance between actors, and the frequency of their interactions. This mobility can take different forms, which deserve further investigation in the future.

Firstly, it can take the form of mobility of the service provision protagonists. This mobility aims to establish an encounter between client and provider. This reflects another intrinsic technical characteristic of services, one long since stressed in the literature: interactivity (service relationship, co-production). Protagonist journeys can take different forms (Gadrey, 2010, Fourcroy et al., 2015): i) service provider travel to the place of service provision (home services, certain sales formulas, consultancy); (ii) consumer or user travel to the place of service production/consumption (hypermarket, restaurant, hotel, hospital, school, university, administration, etc.); (iii) simultaneous service provider and customer travel (transport of persons); and (iv) service company and organization employee travel from their place of residence to their place of work.

These journeys may however also concern the material goods necessary to production of the service: the logistics of material intermediate consumption and the goods that are the medium/target of the service transaction in certain material processing services (for example, supply to stores in retailing, delivery of goods to customers in mail order selling).

As we have pointed out above, mobility-related materiality manifests itself through devices similar to those involved in other sources of materiality, and in particular through logistics and transport systems belonging to either provider or customer ( $\left.T, \mathrm{~T}^{\prime}\right)$, through mobility/circulation spaces (Em): roads, railroad tracks, railway stations, etc.

It should be emphasized that, especially in the field of service management (Levitt, 1972; Shostack, 1984; Eiglier and Langeard, 1987; Lovelock, 1992), there is a huge literature devoted to the mapping and analysis of the various facets of the service transaction we have just mentioned (targets/media, production factors, production/consumption spaces, modalities and systems of mobility). Yet this literature has essentially developed with a focus on the design of innovative services or the identification and analysis of efficient modes of service operation - never, to our knowledge, including ecological concerns. However, the various facets of service mentioned are, as we have suggested, obvious sources of materiality that can only lead to a qualification of the idea of services being immaterial (and therefore green by nature). Their thorough theoretical and empirical exploration deserves to be at the forefront of our research agendas.

\subsection{2 'Horizontal' and 'Vertical' reconsideration of the service frontier}

The theoretical avenues for research outlined above, and in need of pursuit, contribute to a renewal of the question of the definition of services and their perimeter. Indeed, the ecological impact of a service depends on the actual or socially constructed perimeter of that service. Depending on the perimeter chosen, ecological damage will be more or less significant. When it comes to addressing the ecological issue, delineation of the boundaries of a given service transaction must take into account not only of the 'physical' or 'horizontal' 
coordinates (which we began sketching out in paragraph 2.1), but also the temporal or 'vertical' coordinates, focusing on both past and future.

\section{Physical coordinates}

The physical coordinates define, at a given time $\mathrm{t}_{0}$, the various sub-activities (operations) occurring in a given final service transaction. For a given service, these sub-activities cover the various materiality deposits described above (materiality of the target, technical systems and production/consumption spaces), as well as materiality linked to intermediate services that may be mobilized (catering, cleaning, consultancy, etc.). The nature and number of these sub-activities influence the transaction's degree of materiality. To take a simple example, limiting the definition of retailing to the operations carried out within the hypermarket would lead to underestimation of its ecological impact in comparison with a definition in which the service is expanded to include the hypermarket supply and the customer's return trip from home to hypermarket, etc.

\section{Time coordinates}

The second variable needing to be explored in order to establish the boundary of the service and its "materiality balance" is temporal (see Figure 2.2). In this case, all service subactivities and their components that constitute a given service are considered from a life-cycle perspective. Thus, for each technical system (T, $\left.\mathrm{T}^{\prime}\right)$, production space (Ep, Ec, Em), and possible intermediate service $\left(\mathrm{T}^{*}, \mathrm{~T}^{*}, \mathrm{E}^{*} \mathrm{p}, \mathrm{E}^{*} \mathrm{c}, \mathrm{E}^{*} \mathrm{~m}\right)$, materiality and its ecological consequences (energy consumption, $\mathrm{CO}_{2}$ emissions, etc.) are considered both upstream (in $\mathrm{t}$. n) and downstream of the service $\left(t_{+n}\right)$.

The physical coordinates thus reflect a direct materiality of the service transaction linked to the operation of the equipment mobilized during the service (energy consumption and emissions) as well as to the immediate damage caused to natural areas, etc. The temporal coordinates reflect the expression of an indirect materiality, which can be called grey or incorporated materiality. This materiality does not manifest itself at the time of provision of the service in question. It corresponds to the environmental damage associated with the equipment mobilized and real estate infrastructures, during the individual production processes that give rise to them and the recycling processes at the end of their life. 
wealth and take account of the different aspects of sustainability, especially the ecological dimension (Gadrey, 1996; Stiglitz et al., 2009).

Methods for the measurement of grey, embedded or indirect materiality are far more rare because they face the trickier problems of the life cycles of technical systems, material goods, real estate infrastructures, and furniture. However, a limited number of works can be cited which use input-output analysis for variables that are themselves limited. These include, for example, the work of Fourcroy et al. (2015), devoted to grey energy consumption by services, and the work of Alcantara and Padilla (2009) devoted to $\mathrm{CO}_{2}$ emissions. Other studies (IFEN, 2004; Suh, 2006; Alcantara and Padilla, 2009; Nansai, 2009) have sought to estimate greenhouse gas emissions in services. Alcantara and Padilla (2009) conclude that these emissions are almost twice the volume of direct emissions, and IFEN (2004) shows that by reassigning these emissions to final consumption, the contribution made by services to global emissions rises from one quarter to one third.

In any case, given what is at stake, relatively little measurement work is undertaken, especially when it comes to taking into account the indirect nature of services and their ecological consequences. This topic is therefore an important field of research to explore.

One of the major difficulties (and also a research challenge) of these measurement exercises is the need to go beyond linear causalities to account for systemic complexity and the contradictory effects of different sources of materiality. ICTs, for example, have contradictory effects on materiality/sustainability. They exert direct and indirect negative effects on the environment - through, for example, the energy required for their production, operation and recycling. Yet they also have positive effects when used to measure and monitor certain sustainable development indicators, when they are mobilized by citizens in social networks as a way of exerting pressure on public authorities and when, within teleservices (home banking, e-commerce, e-government, videoconferencing, teleworking, telemedicine), they reduce physical journeys and the nuisance these cause. The ecological 'losses' resulting from the introduction of ICT must therefore be deducted from the ecological benefits that result from fewer journeys. In reality, however, calculation of the materiality balance is far more complex. Indeed, certain forms of teleservices (such as mail order) contribute to increasing the circulation of the material goods that are the object of the sale, even though they suppress customer mobility. Beyond this example of teleservice, ICTs have been observed to contribute to an increase in the circulation of goods - in other words, evolutions in information flows and in material flows are positively correlated.

\subsection{BUILDING IMMATERIALITY IN ORDER TO 'GREEN' SERVICES AND GOODS}

Beyond simple observation and measurement of the various sources of materiality/immateriality of the service, the question must be raised of the materialization or dematerialization of the service as a strategic objective for companies and organizations - in other words as a voluntarist innovation strategy. As was pointed out in the introduction to this book (see Advance 14 in Table 2.2), a huge literature exists addressing service materialization and dematerialization strategies. However, because the environmental sustainability issue is not at the heart of these strategies, the second generic avenue for research should try to fill this gap. Although we are primarily interested in dematerialization 
strategies, in order to establish the context, we begin with a brief discussion of the materialization strategies carried out in services companies and organizations.

\subsubsection{Materialization strategies in services}

As we have already pointed out, in a logic of assimilation to the dominant industrial models, Services Studies (particularly within the management field) have theorized and advocated materiality increase or service industrialization strategies (Levitt, 1976). The concerns of the authors involved in these works are managerial in nature, and do not involve any explicit ecological concern. The hypothesis is that the blurred and intangible nature of the service constitutes a hindrance to the efficiency and effectiveness of its production and marketing. Management sciences have thus advocated a transformation of services into quasi-goods, according to various modalities already mentioned: the use of technical systems, the implementation of industrial production methods (Fordism, Taylorism), the addition of goods to the services provided, etc.

Some of these materialization/industrialization modalities immediately seem environmentally unfriendly. This is the case, for example, of materialization through the introduction of technologies or the replacement of services by technologies - that is, achieved through the inclusion of service innovation dynamics in the natural trajectories of increasing mechanization, in the sense of evolutionary economics (Nelson and Winter, 1982). Good examples of this materialization/industrialization modality are encompassed in the theory of the self-service society (Gershuny, 1978), which consists of preferring durable goods used at home to the provision of market services: for example, home use of the washing machine or the DVD instead of the laundromat or cinema.

Other materialization/industrialization modalities seem to have a lesser effect on sustainability from an ecological point of view, even where they affect it from other angles especially social. These modalities aimed to standardize the service through implementation of industrial production methods (invisible technologies) and development of 'flowcharting' (blueprinting) models, which constitute real 'manuals' for service production (Shostack, 1984, Lovelock 1992, Kingman-Brundage, 1992). In this case, industrialization aims to transform services into quasi-products that are homogeneous in space and time: an insurance contract or standard financial product, a standard menu in a fast-food restaurant. The lighter immateriality of this second industrialization/materialization modality of service is only illusory. Indeed, this modality is generally reflected in the increasing use of technologies (ICTs in particular) - and hence in increased materiality.

\subsubsection{Dematerialization strategies in services}

In contemporary economies, services materialization (industrialization) strategies have not disappeared; they maintain a dialectical relationship with inverse dematerialization/customization strategies (see Advance 14 in the general introduction to this book). From the ecological point of view, these service dematerialization strategies (corresponding to innovation strategies) open up new research perspectives. They may also relate to one or more of the sources of materiality mentioned above.

\section{Dematerialization of the medium/target and corresponding operations}

Dematerialization strategies can focus on the medium/target of the service (see Section 2.1). As we have already noted, a service activity is the combination, in variable proportions, of 
processing operations on various, more or less material, media (M, I, K, H) - one of which, depending on the type of service considered, is dominant. Dematerialization strategies refer to innovation strategies involving increasing the relative importance of one intangible function/medium (information and knowledge processing operations) with respect to a tangible function/medium (materials processing operations) that has a strong ecological footprint (see Figure 2.3). Such evolutions can be found in some of the most environmentally damaging materials processing services, such as transport (Djellal, 2000, 2001) or retail (Gallouj, 2007), both of which are characterized by a rise in the intensity of the immaterial components of the service. An operative modality of the strategy for dematerialization of the medium/target is the outsourcing of certain 'material' activities, constituting a service transaction within a given organization: for example, cleaning, catering, logistics, etc. These strategies can thus help reduce the service perimeter - and hence, its materiality.

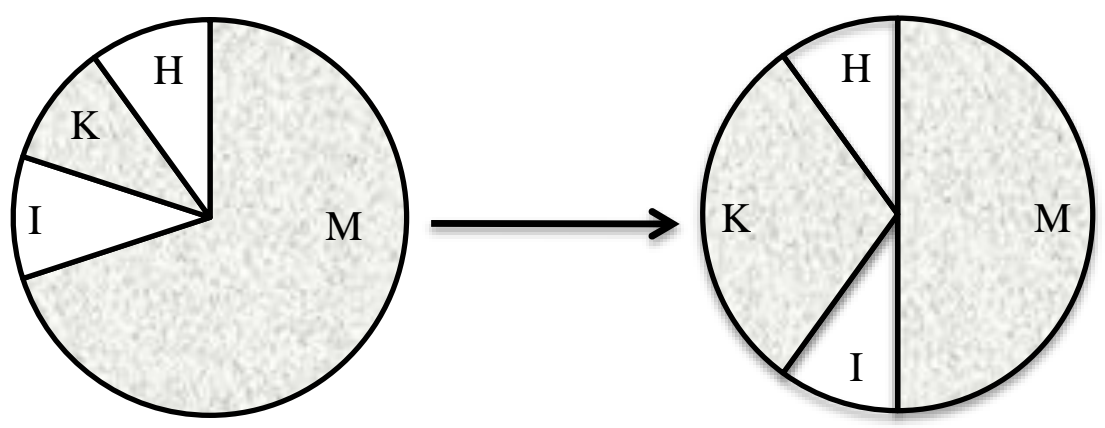

Figure 2.3: Strategy for dematerialization of the medium/target of the service delivery

\section{Dematerialization of technical systems}

Dematerialization strategies can also concern the technical systems used in service transactions. These trajectories can take different forms within a given service organization, and these are worthy of further exploration by Service Innovation Studies.

The first form is the corollary of the service's media dematerialization strategies (preceding point). It reflects a change in the relative weighting of innovation trajectories in favour of intangible trajectories. Indeed, the rise of the information and knowledge processing operations in a given service transaction, to the detriment of material processing operations, has led to a rise in information processing technologies (computers, but especially software) and knowledge processing technologies (invisible technologies: methodologies, protocols), to the detriment of materials processing and transport technologies.

The second form of dematerialization trajectory could be described as intensive. In fact, it reflects a rise in immateriality within a given innovation trajectory, rather than the shift from a material trajectory to a more immaterial trajectory. The idea here is that any component of the service envisaged (whether material, informational, cognitive or human) can be the subject of a green innovation trajectory that is less harmful to the environment. Examples include the design and implementation of cleaner vehicles within the context of logistics material trajectories (electric vehicles), miniaturization processes (reduction of materiality) within the context of material and informational innovation trajectories. 
The third form of dematerialization of innovation trajectories is the hybridization of material and immaterial innovation trajectories. This is illustrated by the rise of smart systems corresponding to the introduction of ICTs to an increasing number of technical systems and infrastructures. One example is the smart grid, which makes it possible to rationalize the use of a technical system in search of sustainability - and energy savings in particular.

The final technical system dematerialization modality necessary to production of the service takes the form of modification of their appropriation and use regimes. This entails substituting collective ownership and consumption (leasing, sharing, pooling, etc.) for individual ownership and private use of these systems.

\section{Dematerialization of production/consumption spaces}

Dematerialization strategies can also be applied to a service's production/consumption spaces. These strategies can take two different forms. The first is the design of alternative production/consumption spaces, helping reduce not only the overall volumes of spaces, but also the number of journeys made. Home services, remote services and shared space services are examples of this type of service dematerialization trajectory. The second form includes all the strategies concerning real estate engineering and architecture (eco-construction, compliance with environmental standards, smart buildings, simplified infrastructures in lowcost services, etc.).

\section{Dematerialization of mobility (instruments)}

These dematerialization/greening trajectories are not independent of the latter two, since in a bid to reduce journeys and their impact on the environment, they introduce technical systems that can stand in for the physical mobility of the provider and user/client. These dematerialization processes are illustrated by the multiple applications of remote services in the fields of health, retailing, banking, administration, etc.: telemedicine, home banking, teleshopping, e-administration, videoconferencing, etc. These are also illustrated by the development of teleworking.

As we pointed out in Section 2.3, in analyzing these different dematerialization/greening strategies, simple linear causalities should not contribute to the overshadowing of systemic complexities and rebound effects.

\subsubsection{The services or service-based dematerialization strategies of goods, and the "everything is service" paradigm}

As we have already pointed out, the two generic strategies (materialization and dematerialization of services) discussed above were neither theoretically nor operationally conceived out of an explicit concern for ecological issues. The research agenda must therefore be developed taking these issues into account, insofar as, as Gadrey (2010) rightly points out, the future of the service economy will depend on the innovation trajectories to be pursued - or more precisely on the degree of dematerialization/greening that will characterize these trajectories. On the contrary, at both theoretical and managerial levels, ecological concerns were included very early on in the goods dematerialization strategies. The main research gap here therefore lies in the question of objective measurement of the effects of goods dematerialization on the ecological issue.

Goods dematerialization strategies (and the corresponding innovation trajectories), also known in the literature as servitization of goods (Vandermerwe and Rada, 1988), can take two 
different operative forms, reflecting what is known as a Product Service System (PSS) (see Goedkoop et al., 1999, Mont, 2002, Tukker, 2004, Baines et al., 2007, Beuren et al., 2013):

- The first and simplest form is the mechanical addition of services to the goods and the creation of what is called an "Object-Oriented Product-Service System" in Tukker's sense (2004). "Object-Oriented PSS" can be categorized along a continuum reflecting the number of 'added' services and their complexity (knowledge intensity). Thus, a more or less large number of services can be added, whether simple (after-sales service, catering, etc.) or complex (consultancy).

- The second form is 'active' dematerialization of the product via the service. This can be achieved once again through the action of either high-level knowledge-intensive services (ecology-oriented consultancy) or more operational services: cleaning, waste treatment, recycling, etc. Indeed, cleaning or sanitation services are materials processing services directly linked to environmental improvement. The same applies to a number of public environmental services such as the maintenance of parks, gardens and forests.

- The third, more abstract, form of servitization (referred to in Paragraph 3.2 on the dematerialization of technical systems mobilized in services) reflects changes in the theoretical conception of goods and their appropriation and consumption patterns and is labelled "Use-Oriented PSS" (Tukker, 2004). The theoretical basis of this third form lies in theories refuting the opposition between product and service on the basis of use value as the common ontological characteristic of the two categories. These integrative theories include the economics of functionality (Stahel, 1997), the economics of experience (Pine and Gilmore, 1999), the characteristics-based approach to the product (Gallouj and Weinstein, 1997), "Service-Dominant Logic" (Lusch and Vargo, 2006), and the new perspective in terms of "Service Science" (Maglio and Spohrer, 2008). With the exception of the economics of functionality (whose main purpose is to construct a theory of sustainable development) the other theoretical approaches mentioned have different concerns, particularly in terms of services marketing and innovation theory. They should be prioritizing the ecological issue in their research agendas.

\section{CONCLUSION}

In contemporary tertiary economies, the environmental issue continues to be characterized by an industrialist and agricultural bias. Industrial and agricultural production processes are described as harmful to the environment by dint of their fundamental nature, which entails transforming material resources (that are not necessarily renewable) in order to produce material products without being able to avoid a certain number of negative externalities (emissions and waste, noise, aesthetic and olfactory nuisances, etc.). With a few exceptions (tourism, transport), services have benefited from an environmentally neutral or positive image that is closely related to their immaterial nature. This (apparent) absence of ecological stakes has led Services Economics and Environmental Economics to essentially ignore one another as they have developed.

The research agenda outlined in this chapter proposes a reconciliation of these two major fields of economic analysis and management - that is, to accord the ecological problem its rightful place in the tertiary sector. The assumption made in this chapter is that services can also be a source of serious environmental nuisances, and that service environmentalfriendliness is closely dependent on the direction of innovation trajectories pursued by service companies and organizations. 
This chapter is thus an invitation to multiply the theoretical and empirical work aimed at identifying the sources of forgotten materiality in service organizations and sectors, and evaluating their ecological impacts (with appropriate tools to be constructed). For various reasons, this undertaking is neither simple nor straightforward. First, because materiality deposits can have direct and indirect effects on sustainability; these must be identified in their physical diversity (perimeter), as well as in a temporal (retrospective and prospective) perspective. Second, because it is necessary to move beyond simple linear causalities in order to address the systemic and dynamic dimension of the relationships between materiality and ecological sustainability. This chapter is also an invitation to undertake both theoretical and empirical exploration of the green innovation (dematerialization) trajectories at work in service companies, organizations and sectors, as well as service (or service-based) green innovation trajectories across the whole economy.

\section{REFERENCES}

Alcantara V. and E. Padilla (2009), 'Input-output subsystems and pollution: an application to the service sector and CO2 emissions in Spain', Ecological Economics, 68 (3), 905-914.

Baines, T.S. et al. (2007), State-of-the-art in product service systems, Proceedings of the Institution of Mechanical Engineers, Part B: Journal of Engineering Manufacture, 221(10), 1543-52.

Baumol, W.J., Blackman, S. A. B. and E. N. Wolff (1985) 'Unbalanced Growth Revisited: Asymptotic Stagnancy and New Evidence', American Economic Review, 75 (September), 806-817.

Bell, D. (1973), The coming of post-industrial society, a venture in social forecasting, New York: Basic Books.

Beuren, F. H., Gomes Ferreira, M. G. and Cauchick Miguel, P. A. (2013), 'Product-service systems: a literature review on integrated products and services', Journal of Cleaner Production, 47 (May), 222-231.

Claval, P. (2006), 'Le développement durable: stratégies descendantes et stratégies ascendantes', Géographie, Economie et Sociétés, 8 (4), 415-445.

Djellal, F. and F. Gallouj (2016), 'Service innovation for sustainability: paths for greening through service innovation', in Toivonen, M. (ed), Service innovation: novel ways of creating value in actor systems, Springer Japan, 187-215.

Djellal, F. (2000), 'The Rise of Information Technologies in "Non-informational" Services', Vierteljahrshefte zur Wirtschaftsforschung, 4 (69), 646-656.

Djellal, F. (2001), Transport routier: la diversité des trajectoires d'innovation, Revue française de gestion, 133 (May), 84-92.

Eiglier, P. and E. Langeard (1987), Servuction. Le marketing des services, Paris: Ediscience international.

Ellger, C. and J. Scheiner (1997), 'After industrial society: service society as clean society? Environmental consequences of increasing service interaction', Service Industries Journal, 17 (4), 564-579.

Ettighoffer, D. (1992), L'entreprise virtuelle. Ou les nouveaux modes de travail, Paris: Editions Odile Jacob.

Fourcroy, C., Gallouj, F., and F. Decellas (2012), 'Energy consumption in service industries: challenging the myth of non-materiality', Ecological Economics, 81 (September), 155164. 
Fourcroy, C., Gallouj, F. and F. Decellas (2015), 'La matérialité invisible des services et ses implications énergétiques : une estimation de l'énergie grise par la méthode input-output', Revue d'économie industrielle, $149,\left(1^{\text {st }}\right.$ trimester $), 43-73$.

Gadrey, J. (1991), 'Le service n'est pas un produit. Quelques implications pour l'analyse économique et pour la gestion', Politiques et management public, 9 (1), March, 1-24.

Gadrey, J. (1996), Services : la productivité en question, Paris: Desclée de Brouwer.

Gadrey, J. (2004), 'Services, croissance, décroissance', Alternatives économiques, $\mathrm{n}^{\circ} 228$, September.

Gadrey, J. (2010), The environmental crisis and the economics of services: the need for révolution, in Gallouj, F. and F. Djellal (eds) (2010), The Handbook of Innovation and Services: a multidisciplinary perspective, Edward Elgar Publishers, pp. 93-125.

Gallouj, C. (2007), Innover dans la grande distribution, Bruxelles: De Boeck.

Gallouj, F. (2002), 'Innovation in services and the attendant old and new myths', Journal of socio-economics, 31 (2), 137-154.

Gallouj, F. and O. Weinstein (1997), 'Innovation in services', Research Policy, 26 (4-5), 537556.

Gershuny, J. (1978), After industrial society? the emerging self-service economy, London: Macmillan.

Goedkoop, M.J., Van Halen, C. J. G., te Riele, H. R. M. and P. J. M. Rommens (1999), 'Product Service Systems, ecological and economic basis', Report for Dutch Ministries of Environment and Economic Affairs, Price Waterhouse Coopers.

Gorz, A. (1988), Métamorphose du travail et quête de sens, Paris: Galilée.

IFEN (2004), 'La tertiarisation de l'économie et la réduction des émissions de $\mathrm{CO}_{2}$ ', Les données de l'environnement, lettre thématique mensuelle de l'IFEN, $\mathrm{n}^{\circ} 95$, September.

Illeris, S. (2007) 'The nature of services', in Bryson J. R. and P. W. Daniels (eds), The handbook of service industries, Cambridge: Edward Elgar, pp. 19-33.

International Energy Agency, (2008), 'Worldwide trends in energy use and efficiency, key insights from IEA indicator analysis, in support of the G8 plan of action', OECD, IEA.

Kingman-Brundage, J. (1992), 'The ABCs of Service System Blueprinting', in Lovelock, C. (ed.), Managing services, Englewood Cliffs, New Jersey: Prentice-Hall International Editions, 96-102.

Levitt, T. (1972), 'Production line approach to service', Harvard Business Review, 50 (September-October), 41-52.

Lovelock, C. (ed) (1992), Managing services, Englewood Cliffs, New Jersey: Prentice-Hall International editions.

Lusch, R. and S. Vargo (2006), 'Service-Dominant Logic: reactions, reflections and refinements', Marketing Theory, 6 (3), 281-288.

Maglio, P. and J. Spohrer (2008), 'Fundamentals of Service Science', Journal of the Academy of Marketing Science, 36 (1), March, 18-20.

Mont, O. (2002), 'Clarifying the concept of product-service system', Journal of Cleaner Production, 10 (3), 237-245.

Nansai, K., Kagawa, S., Suh, S., Fujii, M., Inaba, R. and H. Seiji (2009), 'Material and energy dependence of services and its implications for climate change', Environmental Science and Technology, 43 (12), 4241-4246.

Nelson, R.R. and S. G. Winter (1982), An evolutionary theory of economic change, Cambridge, M., USA and London, UK: Belknap Harvard.

OECD (2000) The service economy, OECD Publications, Paris.

Pine, J. and J. Gilmore (1999), The Experience Economy, Boston: Harvard Business School Press. 
Rifkin, J. (2000), The Age Of Access: The New Culture of Hypercapitalism, Where All of Life is a Paid-For Experience, New York: Putnam Publishing Group.

Romm, J., Rosenfeld, A. and S. Herrman (1999), 'The Internet economy and global warming', The Center for Energy and Climate Solutions.

Say, J.-B. (1972) (First edition 1803), Traité d'économie politique, Paris: Calmann-Levy.

Shostack, G.L. (1984), 'Service Design in the Operating Environment', in George, W., and C. Marshall (eds.), Developing New Services, American Marketing Association, Proceedings Series, 127-143.

Smith, A. (1960). (First edition 1776) The Wealth of Nations, New York: The Modern Library, Random House.

Stahel, W. (1997), 'The Functional Economy: Cultural and Organizational Change', in Richards, D. J. (ed), The industrial green game: implications for environmental design and management, Washington DC: National Academy Press, 91-100.

Stiglitz, J.E., Sen, A. and J.-P. Fitoussi (2009), Report by the commission on the measurement of economic performance and social progress, Paris.

Suh, S. (2006), 'Are services better for climate change', Environmental Science and Technology, 40 (21), 6555-6560.

Tukker, A. (2004), 'Eight types of product-service system: eight ways of sustainability? experiences from SusProNet', Business Strategy and the Environment, 13 (4), 246-260.

Vandermerwe, S. and J. Rada (1988), 'Servitization of Business: Adding Value by Adding Services', European Management Journal, 6 (4), 314-24. 